\title{
Health considerations in the Syrian refugee resettlement process in Canada
}

\author{
Hansen $L^{1 *}$, Huston $P^{2}$
}

\begin{abstract}
Canada has responded to the humanitarian emergency in Syria by committing to welcome 25,000 Syrian refugees by early 2016 . This has been a complex undertaking which required coordination between international organizations, such as the United Nations High Commissioner for Refugees (UNHCR), the International Organization for Migration (IOM) and federal government departments, including Immigration, Refugees and Citizenship Canada (IRCC), the Canada Border Services Agency (CBSA), the Department of National Defence (DND) and the Public Health Agency of Canada (PHAC). Within and across Canada, this initiative has also required the collaboration of provincial and municipal governments, nongovernmental organizations and volunteers, including private sponsors, to enable planning for the transition of Syrian refugees into a new life in Canada.

In planning for the reception of Syrian refugees, government agencies did not anticipate major infectious disease threats. However, early findings from Europe and the experience of health care providers who serve other refugee populations suggested that this population may have other unmet health needs and untreated conditions, due to their experience of displacement over the past three to four years. With this in mind, a great deal of planning has been undertaken to address potential challenges to public health. Social services providers and medical interpreters have been enlisted to help Syrians access the health care system and explain their needs. Communities of practice within Canada have responded, both in providing care and in developing and updating tools and resources to support a culturally sensitive and evidence-based approach to screening and meeting the health needs of the Syrian refugees.
\end{abstract}

Affiliations

${ }^{1}$ Health Security and Infrastructure Branch, Public Health Agency of Canada, Ottawa, ON

${ }^{2}$ Infectious Disease Prevention and Control Branch, Public Health Agency of Canada, Ottawa, ON

*Correspondence: Lisa.Hansen@ phac-aspc.gc.ca

Suggested citation: Hansen L, Huston P. Health considerations in the Syrian refugee resettlement process in Canada. Can Comm Dis Rep 2016;42-Suppl 2:S3-7. https://doi.org/10.14745/ccdr.v42is2a02

\section{Introduction}

The Syrian refugee crisis is a complex humanitarian emergency, defined as a severe socio-political disruption that affects the ability of a population to access the basic necessities of food, water, shelter and physical security (1). Since 2011, Syria has been embroiled in a civil war, complicated by the rise of multiple rebel groups and the Islamic State in Iraq and Syria (ISIS). It is estimated that 250,000 civilians have been killed and about half the country's population of 22 million people have been displaced (2). By November 2015, the United Nations High Commissioner for Refugees (UNHCR) had documented almost four million Syrian refugees (3): Almost two million in Turkey, and over two million in Egypt, Iraq, Jordan and Lebanon. Others have been displaced within Syria, or fled elsewhere in North Africa and Europe.

In light of this humanitarian emergency, in the fall of 2015, the Government of Canada committed to resettle 25,000 Syrian refugees by early 2016 under "Operation Syrian Refugee". This article describes the plan for the identification, screening and resettlement of Syrian refugees immigrating to Canada, with a specific focus on known and anticipated health needs. It also identifies some known challenges to health service provision to refugees, and strategies for how to address them. An accompanying article describes the experience of receiving the Syrian refugees and provides information on their initial health status (4).

\section{Operation Syrian Refugee}

Ensuring a safe and effective resettlement of thousands of refugees is a complex undertaking that involves coordination with foreign governments, international organizations such as the UNHCR, the International Organization for Migration (IOM), and a multiple departments within the Canadian government, including, among others, Immigration, Refugees and Citizenship Canada (IRCC), Canada Border Services Agency (CBSA), Department of National Defense (DND), and the Public Health Agency of Canada (PHAC), as well as provincial, municipal governments, non-governmental organizations and volunteers, including many private sponsors from churches and community organizations. 


\section{Resettlement strategy}

The resettlement strategy is comprised of five phases.

\section{Identifying Syrian refugees to come to Canada}

The UNHCR was responsible for the registration, security screening and selection of Syrian refugees from refugee sites in Lebanon and Jordan. The government of Turkey identified appropriate refugees within its jurisdiction. Immigration and security interviews were conducted by experienced visa officers. The Canadian government stated that priority would be given to the most vulnerable who were a low security risk: Women at risk, complete families and persons who may be discriminated against due to self-identification as lesbian, gay, bisexual, transgender or intersex (LGBTI) (5).

\section{Processing Syrian refugees overseas}

Once cleared from a security perspective, refugees destined for Canada underwent an Immigration Medical Examination (IME), conducted by certified physicians, which is a standard requirement for all immigrants. In normal practice, an immigration applicant may be found inadmissible on health grounds, if his/her health condition is likely to be a danger to public health or public safety, or might reasonably be expected to cause an excessive demand on health or social services (6).

For Operation Syrian Refugee, the IME was primarily used as a screening tool to identify and prioritize health care needs. The results of these tests were treated as confidential and shared with the refugees, including a paper copy of the examination findings with instructions for follow-up, as required. If an applicant was admissible but the IME identified a notifiable infectious disease, such as HIV, syphilis or latent tuberculosis, IRCC notified the appropriate local/regional public health authority in Canada where the refugee was destined.

\section{Transportation to Canada}

After security, medical clearance and the issuance of an exit visa, the plan was for Syrian refugees to travel to Canada primarily through two types of flights. The majority were dedicated charter flights that flew to Toronto or Montréal and a smaller proportion were commercial flights that flew to any international point of entry in Canada. Prior to embarking on their flight, all travellers underwent a "fitness to fly" assessment by the IOM and other partners. This was conducted just before travel to assess whether there were any emergent health issues that would contraindicate travel (such as women in very late pregnancy or active labour) and to facilitate the arrangement of an appropriate level of health care, if needed, upon arrival (7). An IOM escort accompanied all charter flights for refugees destined for Canada.

Most refugees had no obvious medical issues, some were identified to receive routine medical care and, when needed, a few were flagged to receive expedient medical care upon arrival.

\section{Welcoming to Canada}

For the charter flights arriving at either Toronto Pearson International Airport or Montréal Pierre Elliot Trudeau Airport, all refugees were processed as permanent residents, screened for signs of illness and provided with Interim Federal Health Program documents. CBSA officers conducted routine border security checks.

Travellers who appeared ill were assessed by a PHAC quarantine officer. After completing an assessment, quarantine officers determined the appropriate course of action. Based on the assessment and criteria of the Quarantine Act, a traveller could be directed to report to local public health authorities, present for further medical assessment or proceed to his/her eventual destination. When indicated, refugees would be referred immediately to emergency medical teams (EMT) provided by Ontario and Quebec provincial health authorities at the airport areas Welcome Centres. The EMT teams were available on site to assess and treat medical conditions and, where possible, to avoid unnecessary transfers to a hospital. As well, they were available to coordinate with local clinical care and local public health services as indicated (8).

\section{Settlement and community integration}

Once cleared at the point of entry, the Syrian refugees began the transition to their communities. In most cases, in light of the long flights, this began with a brief stay at a hotel near the airport. Privately-sponsored refugees were placed with their sponsors and government-sponsored refugees were transferred to one of 30-35 community-based resettlement assistance programs across the country. Once in their community of destination, some refugees stayed temporarily at local hotels until permanent lodging was available. Interim lodging sites at Canadian Forces bases in Quebec and Ontario, supported by provincial Ministries of Health, the Canadian Red Cross and PHAC $(9,10)$ were also set up as a contingency plan to house refugees. Transitional health services, such as dental health clinics and catch-up vaccination programs, were organized through local health authorities and the provincial health care systems.

Community refugee resettlement agencies have supported refugee integration with language training and social services and by registering children in local schools. The Health Portfolio Operations Centre (HPOC), managed by PHAC, has coordinated the health aspects of the federal response and liaised with provincial and territorial health ministries. Provincial and territorial Ministries of Health have supported the coordination of care within their jurisdictions.

A summary of the arc of assessments of and services for refugees from the identification and screening process in the Middle East to integrating into communities across Canada is illustrated in Figure 1. 


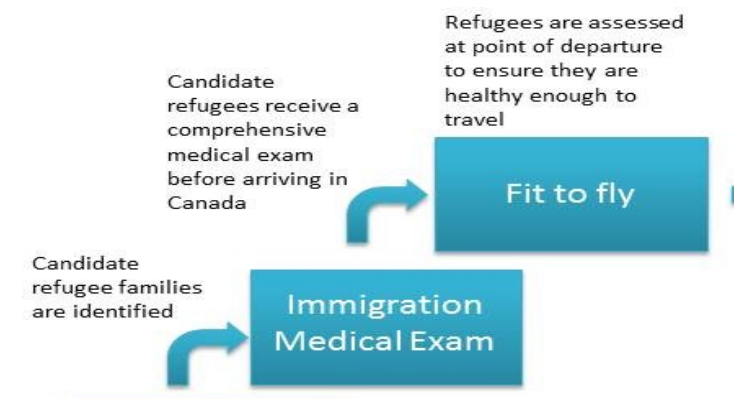

UNHCR and

security

screening

TURKEY, LEBANON, JORDAN

Abbreviation: UNHRC=United Nations High Commissioner on Refugees

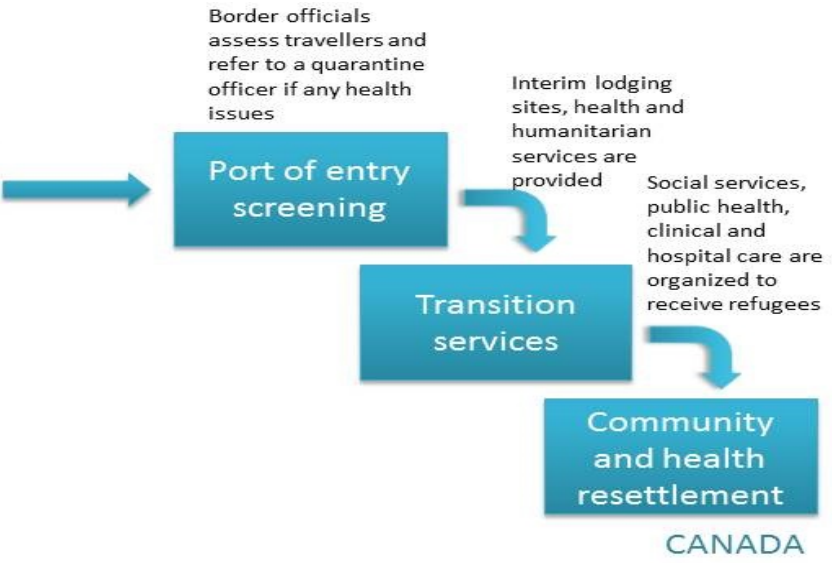

a patient-based guideline for the primary health care of Syrian refugees (11), an evidence-based clinical checklist from the Canadian Collaboration of Immigrant and Refugee Health (15), resources specifically for children from the Canadian Pediatric Society (16) and Syrian-specific mental health resources commissioned by the UNHCR (17).

\section{Public health}

Local and regional public health authorities have worked with health care providers to address the need for catch-up immunizations for Syrian refugees. Routine surveillance processes are in place and may be enhanced, if needed, to assess the impact of large numbers of new arrivals on the health system and to detect and respond to an emerging infectious disease issue (13). Provincial ministries have kept health professionals apprised of health issues as they arise, such as the need for urgent dental care.

\section{Common challenges}

The UNHCR Report has noted the majority of Syrian refugees have demonstrated a remarkable resilience and recover quickly once basic housing, food and security needs are met (16). Nonetheless, it has been anticipated that a small percentage of refugees in Canada will have complex or multiple health care needs. Based on previous experience with large refugee migrations to Canada and elsewhere, there will be inevitable challenges in providing effective health care to refugees.

A major challenge for the newly arrived Syrians will be to ensure they address and prioritize their health issues at a time when they are preoccupied with the resettlement process which includes finding housing, schools, integrating into their communities and finding social circles. In order to ensure the health system is prepared to respond to their health needs, networks of care providers and refugee health experts have begun reaching out to clinicians, providing guidance on expected health issues, including mental health. There is a need to provide appropriate support for these services such as enlisting medical interpreters who are able to translate medical terminology and are also prepared to "bear witness" to the pain and suffering of the refugees' experience. At times interpreters 
may be available only by phone. The use of interpreters with cross-cultural training has been associated with increased confidence of health care providers to care for refugees, better detection of problems at assessment and increased client satisfaction (18).

Based on the UNHCR Report, many Syrian refugees have experienced psychological and social distress after living in a war zone, being displaced from their home and coming to a new country (17). Many have lost family members and friends and may have witnessed or experienced violence. This can lead to emotional reactions (e.g., sadness, grief, anger), physical symptoms (e.g., fatigue, insomnia) and somatic complaints, or social and behavioural problems (e.g. withdrawal or aggression) (17). Refugees' experiences after arriving in Canada may worsen their distress. These post-displacement experiences may include challenges in securing appropriate housing and employment, and overcoming linguistic barriers, discrimination and social isolation (19-21).

Syrians, like other new immigrants, may be uncomfortable discussing feelings of isolation or distress, especially in a new environment. Current recommendations to health care providers are to actively address the health issues but not probe for trauma - as this may make things worse (11) — and to be alert for signs of post-traumatic stress disorder, depression and other mental health problems that may emerge months following arrival in Canada.

In order to address the mental health issues of Syrian refugees, different levels, or layers, of supports and services are indicated (17). The foundational layer is to address the social determinants of mental health, such as safe and adequate housing. The next layer is to assess and optimize family and community supports that foster cohesion among the refugee population. In some cases, focused psychosocial support may be needed to help refugees cope and adjust to Canada. These three layers will help address most mental health issues. If a major mental health issue arises, culturally sensitive mental health services are indicated; the UNHCR resource provides important insights into how this can be done (17).

Health care providers may become overwhelmed with the challenges of addressing the health care needs of refugees. Many health care providers are already oversubscribed and refugee health concerns are another issue that requires preparation and clinical care time. Despite the good intentions and the increasing number of resources available, the demands will be high and there is a risk that health care providers and others may experience compassion fatigue. This can be anticipated and addressed through optimizing the use of support resources offered by professional bodies and organizations, online and telehealth tools, formal and informal support groups and linking with agencies or others with expertise in resilience and addressing the mental health needs of those who respond to crises.

\section{Conclusion}

The Syrian refugees who are coming to Canada have made the difficult decision to leave their once-vibrant, ancient country that has now been devastated by war. Canada is bringing in refugees through a complex collaborative system that involves international organizations, multiple federal departments, provincial and municipal governments, non-governmental organizations and many thousands of volunteers. From a health perspective, the priority is to identify the physical and mental health needs of these newly arrived residents and to create accessible and culturally appropriate services to meet those needs.

There are challenges for the newly arrived Syrians in recovering from the trauma of living through a humanitarian emergency and adjusting to life in Canada. And there are challenges to health care and other service providers in meeting the needs of Syrian refugees. With planning, coordination, resources, mutual support and systems in place to identify emerging issues as they arise, all the components are in place to welcome the Syrian refugees and assist them effectively with their resettlement into Canada.

\section{Acknowledgements}

We wish to thank all those working at international, national, regional and local levels around the world to help bring Syrian refugees into safety.

Note: Dr. Huston is the Editor-in-Chief of the Canada Communicable Disease Report and recused herself from the editorial decisions involved in this article. Many thanks to Dr. Lee Lior for taking on the role as Editor for this article.

\section{Conflict of interest}

None.

\section{References}

1. Gushalak BD, MacPherson DW, Prochazka H, Cooper MM. The practice of immigration halth in complex emergency situations - A case study from Kosovo from March to July 1999. Refuge. 2000;18:46-5.1.

2. Citizenship and Immigration Canada. Population profile: Syrian refugees. Ottawa, ON: CIC; November 2015. http://www.cpa.ca/docs/File/Cultural/EN\%20Syrian\%20 Population\%20Profile.pdf.

3. United Nations High Commissioner for Refugees. Syria Regional Refugee Response. Inter-agency information sharing portal Geneva, SW; United Nations; 2015. http:// data.unhcr.org/syrianrefugees/regional.php.

4. Hansen L, Maidment L, Ahmad R. Early observations on the health of Syrian refugees in Canada. Can Comm Dis Rep 2016;42-Suppl 2:S8-10.

5. Government of Canada. \#WelcomeRefugees: Security and health screening Ottawa, ON: Government of Canada; 2016. http://www.cic.gc.ca/english/refugees/welcome/overview/ security.asp. 
6. Citizenship and Immigration Canada. The immigration medical assessment. Ottawa, ON: Government of Canada; 2016. http://www.cic.gc.ca/english/resources/tools/medic/ assess/using.asp.

7. International Organization for Migration. Migration health annual review 2014 Geneva, SW: IOM; 2015. http:// publications.iom.int/books/migration-health-annualreview-2014.

8. Bhatia N, Sarwal S, Robinson H, Geduld J, Huneault F, et.al. Federal public health strategies to minimize the importation of communicable diseases into Canada. Can Comm Dis Rep. 2015 Suppl 6;41:S3-8.

9. National Defence and the Canadian Armed Forces. Operation PROVISION Ottawa, ON: Government of Canada; 2016. http://www.forces.gc.ca/en/operationsabroad/op-provision.page.

10. Canadian Red Cross. Syrian refugee crisis and refugee arrival in Canada. Ottawa, ON: Canadian Red Cross; 2016. http://www.redcross.ca/how-we-help/migrant-and-refugeeservices/syrian-refugee-crisis-and-refugee-arrival-in-canada.

11. Pottie K, Greenaway C, Hassan G, Hui C, Kirmayer LJ. Caring for a newly arrived Syrian refugee family. Can Med Assoc J. 2015; preprint Dec 8, 2015.

12. Citizenship and Immigration Canada. Interim Federal Health Program. IFHP information handbook for health care professionals. Ottawa, ON: $\mathrm{ClC} ; 2006$. www.medavie. bluecross.ca/cs/BlobServer?blobcol=urldata\&blobtable= MungoBlobs\&blobheadervalue2=abinary; +charset=UTF8\&blobheadername2=MDT-Type\&blobkey=id\&blobwhe $r e=1187213290372 \&$ blobheader=application/pdf.

13. Ontario Ministry of Health and Long-Term Care. Ontario Health System Action Plan: Syrian refugees. Toronto, ON: MOHLTC; December 17, 2015. http://www.health.gov.on.ca/ en/pro/programs/emb/syrianrefugees/docs/health_system_ action_plan.PDF.
14. Canadian Collaboration for Immigrant and Refugee Health (CCIRH) Migrant Health Knowledge Exchange Network. Working together to improve the health of migrants. Ottawa, ON: CCIRH; 2015. http://www.ccirhken.ca/index. html.

15. Canadian Collaboration for Immigrant and Refugee Health (CCIRH). Evidence-based clinical e-checklist for immigrants. Ottawa, ON: CCIRH; 2015. http://www.ccirhken.ca/ccirh/ checklist_website/index.html.

16. Canadian Pediatric Society. Caring for kids new to Canada website. Ottawa, ON: CPS; 2015. http://www. kidsnewtocanada.ca/.

17. Hassan G, Kirmayer LJ, Mekki-Berrada A, Quosh C, el Chammay R, Deville-Stoetzel, et al. Culture, context and the mental health and psychosocial wellbeing of Syrians: A review for mental health and psychosocial support staff working with Syrians affected by armed conflict. Geneva, SW: UNHCR, 2015. http://mhpss.net/?get=250/Culture _ mental-health_Syrians-FINAL1.pdf.

18. Joshi C, Russell G, Cheng IH, Kay M, Pottie K, Alston M, et al. A narrative synthesis of the impact of primary health care delivery models for refugees in resettlement countries on access, quality and coordination. Int J Equity Health. 2013 Nov 7;12:88. http://www.ncbi.nlm.nih.gov/pmc/articles/ PMC3835619/pdf/1475-9276-12-88.pdf.

19. Campbell M. Social determinants of mental health in new refugees in the UK: Cross-sectional and longitudinal analyses. Lancet. 2012;380:S27.

20. Wilson RM, Murtaza R, Shakya YB Pre-migration and post-migration determinants for newly arrived refugees in Toronto. Canadian Issues: Immigrant Mental Health. Summer 2010:45-50.

21. Mawani F. Social determinants of refugee mental health. In Simich L, Andermann L (eds.) Refuge and resilience: Promoting resilience and mental health among resettled refugees and forced migrants (International Perspectives on Migration, Vol. 7). Berlin: Springer Science + Business Media; 2014. 